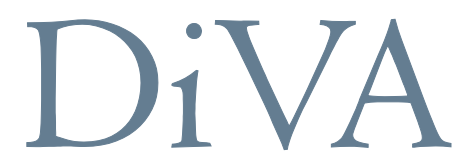

http://uu.diva-portal.org

This is an author produced version of a paper published in Energy. This paper has been peer-reviewed but does not include the final publisher proof-corrections or journal pagination.

Citation for the published paper:

Li, J., Dong, X., Shangguan, J. \& Höök, M.

"Forecasting the growth of Chinese natural gas consumption"

Energy, 2011, Vol. 36, Issue 3: 1380-1385

URL: http://dx.doi.org/10.1016/i.energy.2011.01.003

Access to the published version may require subscription. 


\title{
Forecasting the growth of Chinese natural gas consumption
}

\author{
Junchen $\mathrm{Li}^{*}$, Xiucheng Dong ${ }^{*}$, Jianxin Shangguan ${ }^{\#}$, and Mikael Höök ${ }^{+}$ \\ * School of Business and Administration, China University of Petroleum, Beijing 102249, China \\ \# Marketing Company of PetroChina, Beijing 100007, China \\ + Global Energy Systems, Uppsala University, Uppsala 75321, Sweden
}

\begin{abstract}
The use of natural gas in China is still relatively immature, as gas production only supplies a low percentage of the domestic energy system. In contrast, the Chinese economy mainly relies on coal with a $67 \%$ share of the total primary energy supply. The environmental impact from this high coal dependence is significant and planners have sought for cleaner energy sources. Natural gas is both cleaner and generally more efficient than coal and gas consumption is rising quickly due to these facts.

The growth tendency indicates that natural gas will become an important substitution for coal in some parts of the Chinese primary energy consumption. To quantify this tendency, this paper uses a system dynamics model to create a possible outlook. The results show that the gas consumption in China will continue to increase fast to 89.5 billion cubic meters in $2010 ; 198.2$ billion cubic meters in 2020, before finally reaching 340.7 billion cubic meters in 2030 .

It is also found that the consumption structure will change and scenario analysis was used to assess this closer. Finally, this paper gives some policy suggestions on natural gas exploration and development, infrastructure constructions and technical innovations to promote a sustainable development of China's natural gas industry.
\end{abstract}

Key words: natural gas consumption; system dynamics model; scenario analysis 


\section{Introduction}

The first account of natural gas consumption in China dates back to about 3000 years ago and marks the first attempt to explore and use this gaseous energy source. Although China has a long history of gas utilization, the domestic natural gas industry in China developed slowly during its industrializing period.

Natural gas is generally considered as a clean and efficient fossil fuel, making it attractive as an energy source. Percentage of primary energy supply originates from natural gas is high in many countries. In 2008, natural gas consumption supplied $24.1 \%$ of the total primary energy consumption of the world [1]. In contrast, Chinese natural gas consumption only accounted for $3.7 \%$ of the domestic energy need.

The low gas percentage was led by the former energy utilization policies. In 1949, a development pattern was established that mainly focused on coal as the primary energy source due to abundant coal resources in China. In the wake of the increasing coal dependence many problems emerged such as air pollution, water contamination, greenhouse gas emission, etc. In recent years, the government has begun to recognize the disadvantages of the high reliance on coal. According to current policies, natural gas will be developed as a partial substitution for coal.

Since the dawn of the 21st century, gas consumption in China has soared and continues to rise fast. New exploration has been undertaken and proved gas reserves have constantly been increasing (Figure 1). The ultimately recoverable gas resources have been estimated to 22 trillion cubic meters [2], mainly originating from the Tarim basin, Erdos basin and offshore. In addition, the Chinese government has collaborated with foreign countries to import gas. By combining indigenous and foreign gas resources, China can reasonably get enough gas to satisfy the growing consumption for the near term. Rising use of natural gas also results in a changing primary energy consumption structure with a higher reliance on gas. This is beneficial for both the environment and the continued sustainable development of the Chinese economy.

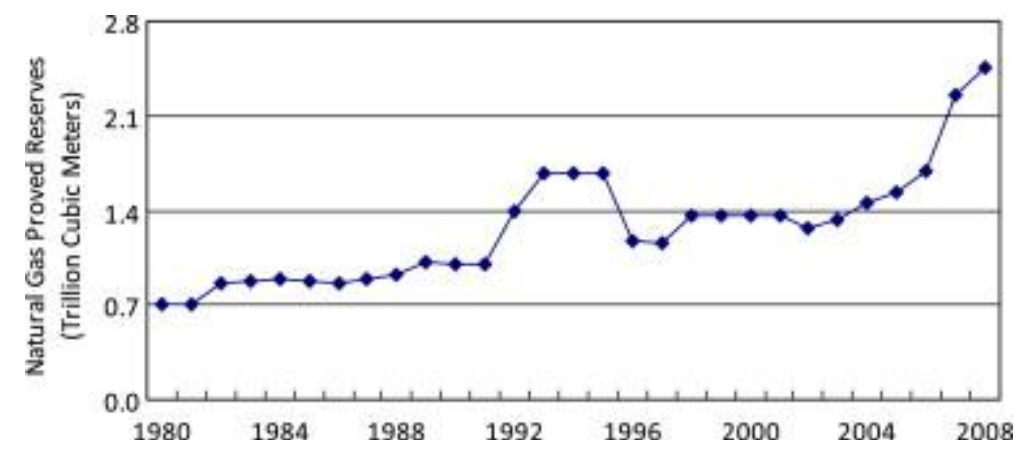

Figure 1. Proved reserves of China's natural gas. Data source: [1]. 


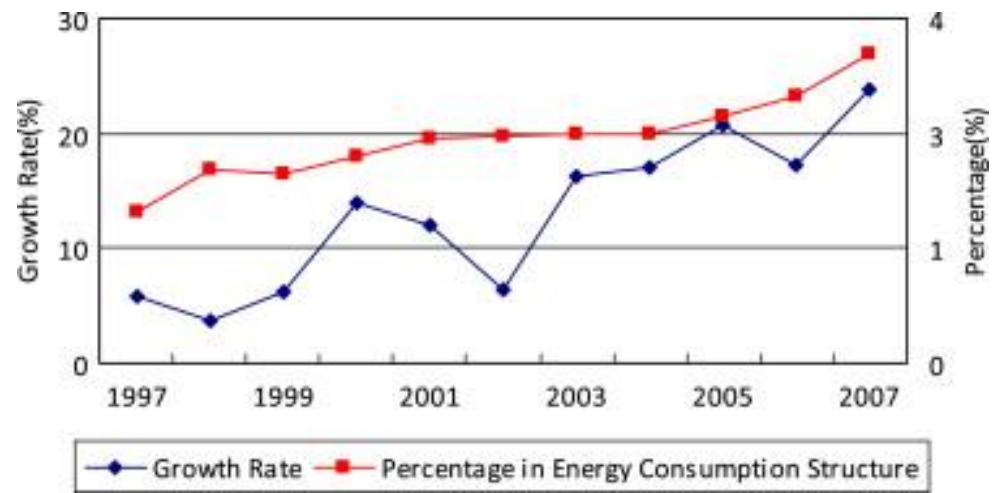

Figure 2. Natural gas growth in China. Data source: [1].

\section{Modeling}

\subsection{Model introductions}

Many experts have developed methods to forecast natural gas consumption. In foreign countries, neural networks were used for short-term outlooks and obtained good results [4]. Additional models emerged as forecasting methodology progressed, including the metric models. Noureddine [5] included impact factors from natural gas production, natural gas price, GDP level, etc. in the modeling. Further developments were made by Eugenio et al. [6] as additional impact factors from seasonal changes and the unexpected incidents were included.

Some other metric models, such as degree-day method [7], Gompertz model [8], nonliner congressional model [9], ARIMAX model [10] and MARKAL model [11], were also useful under specific conditions. Besides model development, many other works have projected natural gas consumption trends into the future [12], [13] and [14]. Relationship between gas consumption and environment is another vital topic [15], [16] and [17].

In China, Qian [18] summarized and compared various natural gas consumption forecast approaches. Wang et al. [19] brought out the first metric model for forecasting natural gas consumption in China. After that, other researchers used more exotic models like Fourier functions [20], grey neural network [21], combination models [22] and [23], or self-organizing data mining method [24]. All these models provided different ways to depict trends in natural gas consumption and were considered useful for planning gas industry development.

There are many forecasting approaches, but it must be understood that there are significant difficulties with establishing an accurate model due to the complexity of the natural gas consumption. Many factors such as production strategies, industry policy, GDP growth, infrastructure construction, changing demand patterns and similar cannot be fully considered in many models. To remedy this shortcoming, this study uses a system dynamics approach since it easily can include numerous interdependent factors.

The system dynamics approach was established by Professor Forrester of MIT in 1956 as a way to handle production and storage problems in enterprises. Now it is widely used in countless fields, including strategic planning, public management, and energy planning. Within this framework, natural gas consumption can be seen as a complicated system of different impact factors in with interdependent feedbacks. 


\subsection{Model assumptions}

In this study, natural gas is referred to as only conventional gas, excluding the unconventional resources, such as landfill gas, biogas, coal bed methane, and so on. China's good relationship with some main gas exporters such as Turkmenistan and Kazakhstan ensures the continued gas imports. In 2008, China imported 4.44 billion cubic meters of gas in the form of LNG (Liquefied Natural Gas). In future, the gas import is assumed to keep on increasing because of the demand and additional pipeline constructions. Together with the underdeveloped domestic gas resources, it can be assumed that gas production is able to meet rising demand. In essence, the model assumes that the availability of natural gas is good.

Before the actual modeling, it is necessary to divide the Chinese natural gas consumption system into four subsystems according to the economy structures: Primary Industry consumption (PIC); Secondary Industry consumption (SIC); Tertiary Industry consumption (TIC) and Residential consumption (RC) as shown in Figure 3. The consumption of each subpart and the total consumption tendency are shown in Figure 4. PIC refers to the natural gas consumed by agriculture and this part is insignificant, hence it is not considered in the model. The largest share of natural gas consumption comes from SIC. As a result, this part is divided into the additional subcategories: (1) chemical industry consumption (CIC) including ammonia, methyl alcohol and related chemical industries, (2) power generation consumption (PGC), and (3) industrial fuel consumption (IFC) for more detailed analysis.

In 2007, CIC alone accounted for $36.4 \%$ of total gas consumption. CIC consumption had decreased slowly in the past because of the rapid development of some other consumption fields, but it still remained the largest consumption sector. IFC showed similar tendency as CIC and used $27.0 \%$ of the natural gas in 2007. PGC had increased steadily and broke the $10.0 \%$ threshold in 2007. Natural gas-fired power plants have advantages such as high efficiency and little pollution, so it is attractive as a contributor in the power generation grid. In 2007, the percentage of power generation derived from coal was $83.2 \%$, while natural gas only accounted for $0.5 \%$ [25]. Tertiary industry consumption (TIC) includes services such as transportation, catering industry, and similar sectors.

It accounted for $9.3 \%$ of the total gas consumption in 2005 , but decreased to $7.2 \%$ in 2007. Residential Consumption (RC) can be treated as the consumption of city gas. This part is consumed by urban people in daily life. In 2007, RC accounted for $19.2 \%$ of the total gas consumption in China. The development of natural gas consumption for residential purposed is encouraged by government. Because of this policy, RC is expected to continue its growing.

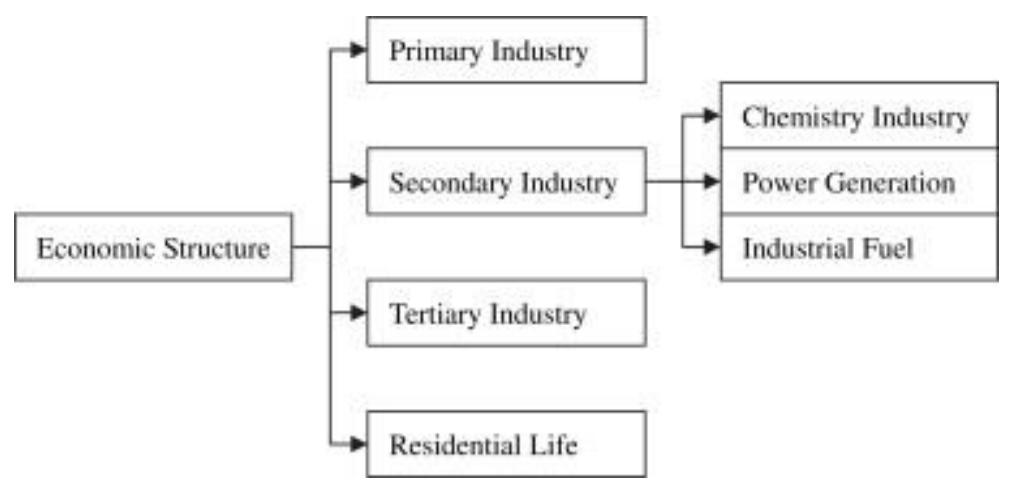

Figure 3. China's economy structure. 


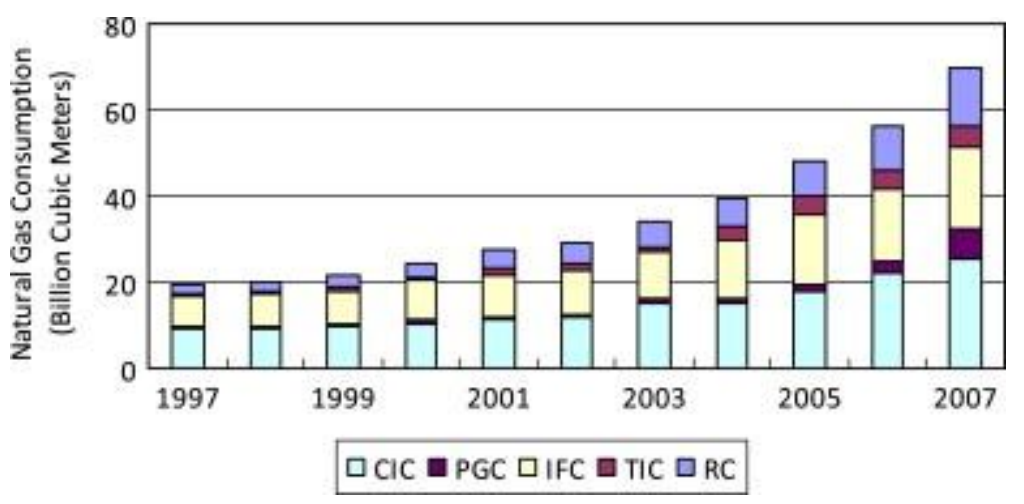

Figure 4. Natural gas consumption structure in China. Data source: [25].

\section{Forecasting}

The model framework is established using the popular system dynamics software STELLA, which is better described by Tao [26]. STELLA offers a practical way to dynamically visualize interactions in complex systems. The consumption forecast model is shown in Figure 5.

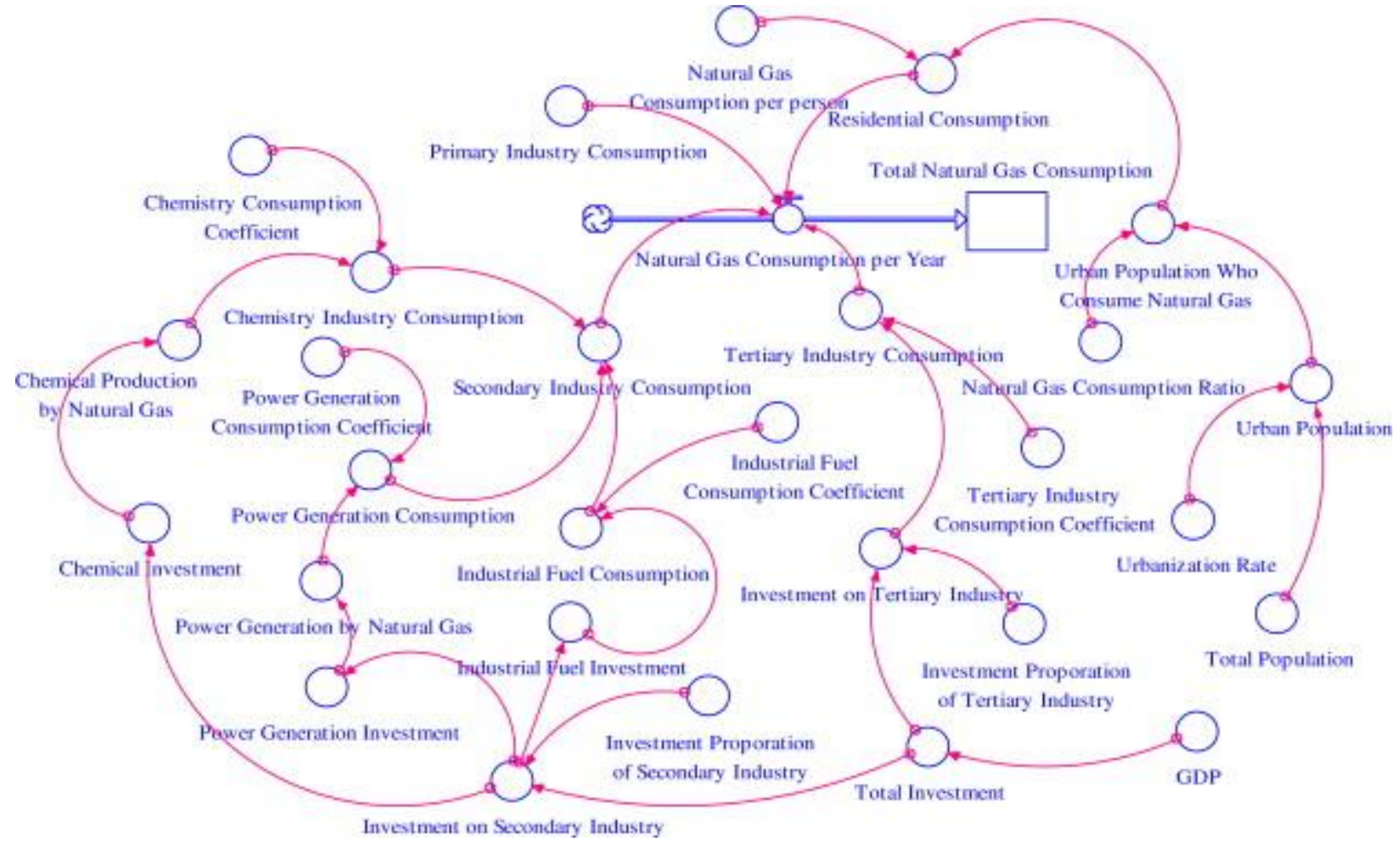

Figure 5. System dynamics model for China's natural gas consumption.

The consumption of different sectors is forecasted separately to better capture the reality of the Chinese economic structure. According to the model, growth of industry consumption depends on investment, while residential consumption is governed by total population. GDP and 
industry investment have a close relationship that will be discussed more closely in the next section. In essence, GDP and total population are the dominant two key factors for projecting future natural gas consumption.

In addition, both the domestic and international gas prices are other important factors for gas consumption. In many other countries, price should definitively be taken into consideration when forecasting consumption. However, the situation is a bit different in China. The Chinese administration has imposed a price control system on natural gas, so the price cannot fluctuate significantly. Because of this, gas import companies have to import gas with high international price and sell it with lower government price. Considering this, we do not treat price as an important factor in our consumption forecast.

\subsection{GDP and total population forecast}

(1) The GDP factor was taken from the Development Research Center of the State Council (2005). Their projection for future GDP was showed in Table 1, and was calculated according to constant prices of year 2005. Using this source, we assumed that China's GDP growth rate would decrease gradually in the system dynamics model.

Table 1. GDP and the growth rate.

\begin{tabular}{|llllll|}
\hline Year & $\mathbf{2 0 0 7}$ & $\mathbf{2 0 1 0}$ & $\mathbf{2 0 1 5}$ & $\mathbf{2 0 2 0}$ & $\mathbf{2 0 3 0}$ \\
\hline GDP(Billion Yuan) & $22,889.8$ & $28,914.8$ & $41,510.9$ & $57,679.1$ & $97,594.2$ \\
\hline Year & $2007-2010$ & $2011-2015$ & $2016-2020$ & $2021-2030$ \\
\hline Growth rate & $8.1 \%$ & $7.5 \%$ & $6.8 \%$ & $5.4 \%$ \\
\hline
\end{tabular}

Data source: Development Research Center of the State Council, "Economy growth of China", 2005.

(2) Total Population projections were taken from the "2007 Report of National Population Development Strategy" from National Population and Family Planning Commission of China. It showed the basic strategy of China's population development. The expected future population trend and urbanization level used in the model were presented in Table 2.

Table 2. Future population of China.

\begin{tabular}{|l|l|l|l|l|l|}
\hline Year & $\mathbf{2 0 0 7}$ & $\mathbf{2 0 1 0}$ & $\mathbf{2 0 1 5}$ & $\mathbf{2 0 2 0}$ & $\mathbf{2 0 3 0}$ \\
\hline Population (billion) & 1.32 & 1.36 & 1.40 & 1.45 & 1.47 \\
\hline Urbanization & $44.9 \%$ & $47.0 \%$ & $49.9 \%$ & $53.0 \%$ & $55.5 \%$ \\
\hline
\end{tabular}

Data source: National Population and Family Planning Commission of China, "National Population Development Strategy", 2007. 


\subsection{Key assumptions}

Historical data show the close relationship between GDP and total investment in the natural gas sector. The relationship can be described as a linear trend with regression methods as shown in Equation 1. If future GDP is known, the investment tendency can be estimated. From Table 1, the investment forecast which is calculated in constant price of year 2005 is shown in Figure 6.

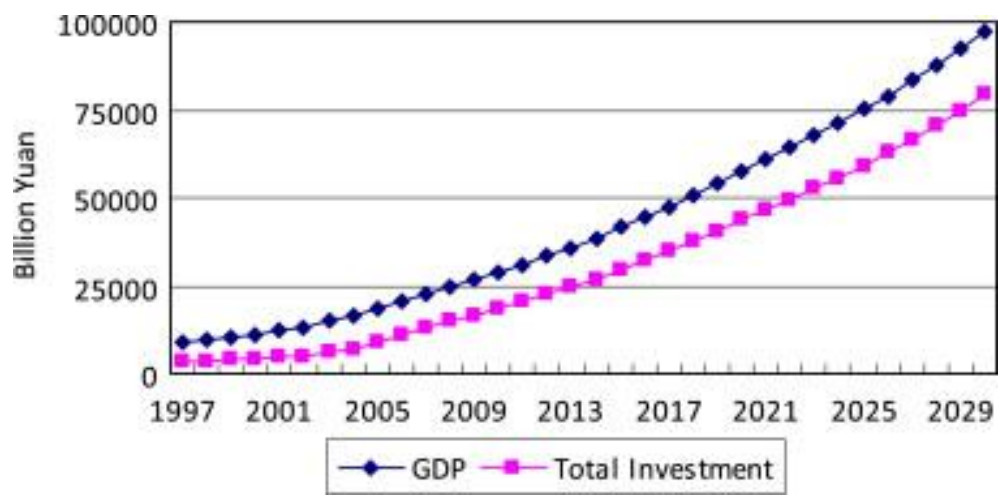

Figure 6. Total investment forecast.

For modeling reasons, investment proportions of primary industry, secondary industry and tertiary industry are necessary in further research. For simplicity, the future investment proportion is assumed to be constant. The historical proportions and the assumed future proportion are shown in Table 3.

Table 3. Investment proportions of different industries.

\begin{tabular}{|l|l|l|l|}
\hline Year & $\mathbf{2 0 0 5}$ & $\mathbf{2 0 0 7}$ & Assumed future \\
\hline Primary industry & $2.6 \%$ & $2.5 \%$ & $2.0 \%$ \\
\hline Secondary industry & $43.7 \%$ & $44.6 \%$ & $45.0 \%$ \\
\hline Chemistry & $5.0 \%$ & $5.5 \%$ & $5.4 \%$ \\
\hline Power generation & $8.5 \%$ & $6.8 \%$ & $6.8 \%$ \\
\hline Industrial fuel & $30.2 \%$ & $32.3 \%$ & $32.8 \%$ \\
\hline Tertiary industry & $53.6 \%$ & $53.0 \%$ & $53.0 \%$ \\
\hline
\end{tabular}

There are many different consumption coefficients in system dynamics model. Chemistry consumption coefficient comes from the ratio of the historical CIC to corresponding historical chemistry production. Power generation consumption coefficient means the gas consumption per unit power generation. In China, this coefficient is 0.2 if the generation equipment's efficiency is $50 \%$ [25]. Industrial fuel coefficient is taken as the ratio of historical IFC to corresponding historical investment on industrial fuel. Tertiary industry consumption coefficient is estimated in the same way as industrial fuel coefficient.

In the "residential consumption" subsystem, natural gas consumption ratio means the percentage of population which consumes natural gas in total urban population. In the urbanized parts of China, people can chose to use coal gas, LPG (liquid petroleum gas), or natural gas. The 
natural gas consumption ratio has increased historically and reached $17.2 \%$ in 2007 . We assume that this ratio will keep on increasing because of high efficiency and continuous infrastructure construction in cities. The ratio is assumed to reach $33.9 \%$ in $2020 ; 37.2 \%$ in $2025 ; 39.5 \%$ in 2030 .

\subsection{Forecast results}

Historical data from 1997 to 2007 along with the forecast results are shown in Figure 7. Chinese natural gas consumption is estimated to reach 89.5 billion cubic meters in 2010, 198.2 billion cubic meters in 2020 , before finally reaching 340.7 billion cubic meters in 2030 . The average growth rate is $7.2 \%$. There is a strong potential for the rapid development of domestic natural gas industry in China.

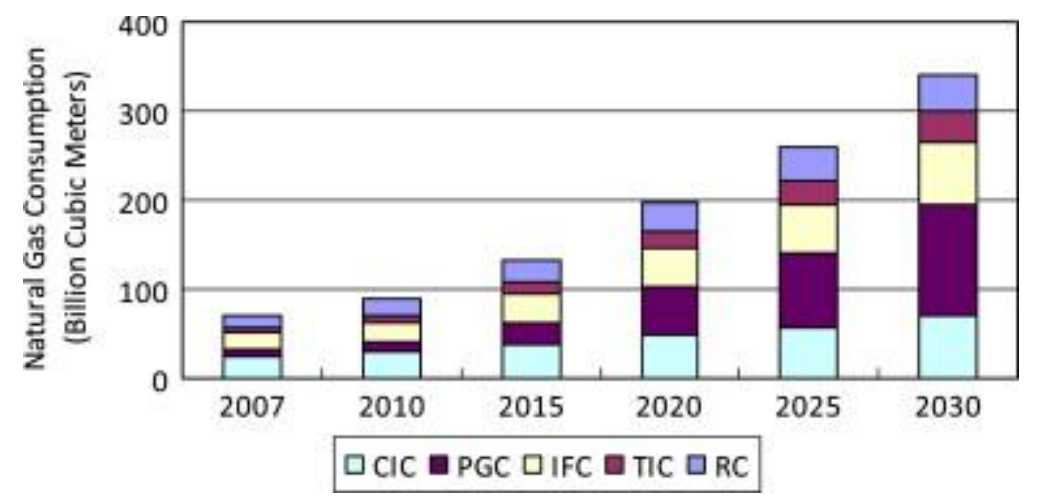

Figure 7. China's natural gas consumption forecast results.

Every subsystem is projected to consume more natural gas, but the consumption structure will change because of different internal growth rates. In Secondary Industry, PGC will grow $13.3 \%$ on average, reaching 53.3 billion cubic meters in 2020 , and 124.5 billion cubic meters in 2030. The corresponding percentage in total natural gas consumption is $26.9 \%$ and $36.5 \%$. In contrast, CIC will increase slowly with an average growth rate of only a mere $4.5 \%$. In effect, the CIC ratio in total natural gas consumption will decrease from $36.4 \%$ in 2007 to $20.2 \%$ in 2030 .

IFC will reach 43.2 billion cubic meters in 2020 before reaching 70.7 billion cubic meters in 2030 with a growth rate of $5.9 \%$. The percentage of IFC in total natural consumption will also decrease. TIC will grow by $8.9 \%$, reaching 19.2 billion cubic meters in 2020 and 35.0 billion cubic meters in 2030. The TIC share of total gas consumption increases from $9.7 \%$ and $10.3 \%$. Finally, RC will reach 33.6 billion cubic meters in 2020 and 41.6 billion cubic meters in 2030 and the average growth rate is $5.1 \%$. More and more urban people will prefer natural gas as their energy source in future according to the model results.

\section{Scenario analyses on total consumption}

The system dynamics model is built on several assumptions, each containing uncertainty that will be passed on to the forecast. To reduce this uncertainty, one may apply scenario analysis to investigate different outcomes depending on alterations in the underlying assumptions.

Three different scenarios are established and categorized as high, reference and low cases. Parameters like GDP, total population, urbanization rate and investment proportions of different industries are chosen to reflect the storylines of the different scenarios. The different cases and their assumed parameters are shown in Table 4. 
Table 4. Parameters assumptions of different scenarios.

\begin{tabular}{|c|c|c|c|c|c|c|c|}
\hline Parameters & & Scenarios & 2007 & 2010 & 2015 & 2020 & 2030 \\
\hline GDP (billion yuan) & & High level & $\begin{array}{l}22,889 \\
8\end{array}$ & $\begin{array}{l}29,237 \\
.0\end{array}$ & $\begin{array}{l}43,356 \\
.9\end{array}$ & $\begin{array}{l}66,848 \\
.0\end{array}$ & $\begin{array}{l}116,83 \\
2.2\end{array}$ \\
\hline & & $\begin{array}{l}\text { Reference } \\
\text { level }\end{array}$ & $\begin{array}{l}22,889 \\
.8\end{array}$ & $\begin{array}{l}28,914 \\
.8\end{array}$ & $\begin{array}{l}41,510 \\
.9\end{array}$ & $\begin{array}{l}57,679 \\
.1\end{array}$ & $\begin{array}{l}97,594 \\
2\end{array}$ \\
\hline & & Low level & $\begin{array}{l}22,889 \\
.8\end{array}$ & $\begin{array}{l}28,436 \\
.0\end{array}$ & $\begin{array}{l}40,257 \\
.0\end{array}$ & $\begin{array}{l}55,675 \\
.5\end{array}$ & $\begin{array}{l}94,204 \\
1\end{array}$ \\
\hline Population (billion) & & High level & 1.32 & 1.34 & 1.36 & 1.39 & 1.45 \\
\hline & & $\begin{array}{l}\text { Reference } \\
\text { level }\end{array}$ & 1.32 & 1.36 & 1.40 & 1.45 & 1.47 \\
\hline & & Low level & 1.32 & 1.38 & 1.42 & 1.47 & 1.49 \\
\hline Urbanization & & High level & $44.9 \%$ & $47.2 \%$ & $51.3 \%$ & $55.8 \%$ & $58.3 \%$ \\
\hline & & $\begin{array}{l}\text { Reference } \\
\text { level }\end{array}$ & $44.9 \%$ & $47.0 \%$ & $49.9 \%$ & $53.0 \%$ & $55.5 \%$ \\
\hline & & Low level & $44.9 \%$ & $46.3 \%$ & $48.7 \%$ & $51.2 \%$ & $52.7 \%$ \\
\hline $\begin{array}{l}\text { Investment proportions } \\
\text { of different industries }\end{array}$ & Primary industry & High level & $2.5 \%$ & $1.5 \%$ & & & \\
\hline & & $\begin{array}{l}\text { Reference } \\
\text { level }\end{array}$ & $2.5 \%$ & $2.0 \%$ & & & \\
\hline & & Low level & $2.5 \%$ & $2.5 \%$ & & & \\
\hline & $\begin{array}{l}\text { Secondary } \\
\text { industry }\end{array}$ & High level & $44.6 \%$ & $43.0 \%$ & & & \\
\hline & & $\begin{array}{l}\text { Reference } \\
\text { level }\end{array}$ & $44.6 \%$ & $45.0 \%$ & & & \\
\hline & & Low level & $44.6 \%$ & $47.0 \%$ & & & \\
\hline & Tertiary industry & High level & $53.0 \%$ & $55.5 \%$ & & & \\
\hline & & $\begin{array}{l}\text { Reference } \\
\text { level }\end{array}$ & $53.0 \%$ & $53.0 \%$ & & & \\
\hline & & Low level & $53.0 \%$ & $51.5 \%$ & & & \\
\hline
\end{tabular}

Compared with the reference level, high level and low level have their own characters. In the high scenario, China's GDP will grow faster and reach 116,832.2 billion Yuan by 2030. The society will be richer and population growth is lower due to more rapidly decreasing birth rates in the wake of increasing welfare. Urbanization level will increase and more investments are made in the Tertiary Industry category. The low scenario contains an assumption of slower growth rates for GDP, essentially implying that the Chinese society will develop less rapidly. The total population will be larger, but the urbanization level is much lower. Investments in secondary industry will increase as the economic growth will still be dominated by the secondary industry category. In essence, the three scenarios describe different development paths for China. Using the same model, the forecasted natural gas consumption of different scenarios is shown in Figure 8. 


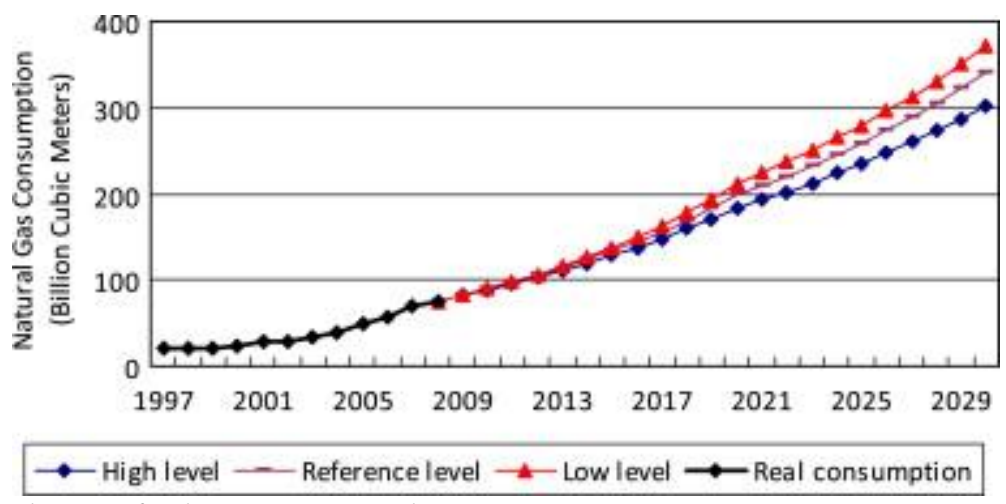

Figure 8. Scenario analysis of China's natural gas consumption.

Gas consumption in the low case scenario is the largest, while consumption of high level is the smallest. This is explained by the fact that the high case is mainly relying on tertiary industry. However, all results show the Chinese natural gas consumption will increase quickly.

IEA [27] has also forecasted China's natural gas consumption and estimates that it will be between 180 and 200 billion cubic meters in 2020. This is in good agreement with the outcomes between the high and reference scenarios presented in this study. Table 5 compiles the forecasted consumption figures for the three scenarios.

Table 5. Natural gas consumption in future (billion cubic meters).

\begin{tabular}{|l|l|l|l|}
\hline Year & High level & Reference level & Low level \\
\hline 2010 & 88.7 & 89.5 & 89.9 \\
\hline 2015 & 128.6 & 133.1 & 137.8 \\
\hline 2020 & 183.0 & 198.2 & 211.4 \\
\hline 2030 & 302.7 & 340.7 & 370.5 \\
\hline
\end{tabular}

\section{Conclusions}

The rising importance and preference of natural gas in China make consumption forecasts essential for strategic planning. The system dynamics model used in this paper is a comprehensive approach that we believe integrates the abilities of many other approaches. From the mode, it's shown that natural gas consumption in China will keep a rapidly growing tendency. Consumption is estimated to reach 89.5 billion cubic meters in 2010, 198.2 billion cubic meters in 2020, and finally 340.7 billion cubic meters in 2030. In addition, the consumption structure will change. To obtain more holistic results, a scenario analysis is undertaken.

The future development of natural gas in China will inevitability impact other fossil fuel industries, in particular coal. Natural gas has advantages in terms of efficiency, cleanness and $\mathrm{CO} 2$ emissions, which is attractive for substituting a part of the coal consumption. However, this competition will likely reduce the number of available jobs in the coal sector. But on the other hand, new jobs will be created within the growing gas industry. In addition, a reduced consumption of coal could also lead to a more sustainable energy system as well as preserving domestic natural resources. 
Good planning for meeting this rapid consumption growth is imperative for the Chinese society. The government has already made some efforts, including the following measures:

(1) Promoting new exploration and development of natural gas reserves, especially in the southwest and northwest regions of China. The current estimation of natural gas resources indicates a URR of 22 trillion cubic meters, mainly distributes in southwest and northwest of China.

(2) Promoting infrastructure construction and gas pipeline networks. The length of gas pipeline currently exceeds $30,000 \mathrm{~km}$. However, this can't satisfy the total transport demand. Additional construction activities will likely lead China into a golden age of pipeline construction.

(3) Gas import is simply unavoidable in future. It is vital to assess the potential for various countries to act as gas exporters of China. This includes political studies, gas reserve estimation, and economy estimation, and other relevant parameters. At present, China relies on Central Asian countries as the foreign gas suppliers. It is vital to maintain good relationships with these countries, especially in light of the future situation where China would need to import more and more natural gas. Seeking new suppliers and forging new relationships and collaborations in the gas sector are also essential.

In summary, the availability of natural gas from indigenous and foreign is crucial for meeting the fast growing gas consumption. Further effort must be taken based on the projected growing tendency of gas consumption to achieve a sustainable development of China's natural gas industry.

\section{References}

[1] BP statistical review of world energy, BP (2009).

[2] New round of assessment on oil and gas resources, China Ministry of Land and Resources (2005).

[3] Qiu ZJ. China's natural gas industry will meet rapid growth of "golden time"; 2008. Available from: http://www.xj.cei.gov.cn/e/DoPrint/?classid=39\&id=32037.

[4] D.C. Park, M.A. El-sharkawi, R.J. Marks, L.E. Atlas and M.J. Damborg, Electric load forecasting using an artificial neural network, IEEE Transactions on Power Systems 6 (1991), pp. 442-448.

[5] K. Noureddine, World crude oil and natural gas: a demand and supply model, Energy Economics 24 (2002), pp. 557-576.

[6] F. Eugenio, Sánchez-Úbeda and B. Ana, Modeling and forecasting industrial end-use natural gas consumption, Energy Economics 29 (2007), pp. 710-742.

[7] H. Sarak and A. Satman, The degree-day method to estimate the residential heating natural gas consumption in Turkey: a case study, Energy 9 (2003), pp. 929-939.

[8] R. Gutiérrez, A. Nafidi and S.R. Gutiérrez, Forecasting total natural-gas consumption in Spain by using the stochastic Gompertz innovation diffusion model, Applied Energy 80 (2005), pp. 115-124.

[9] V. Jiri, P. Emil, O. Konar, C. Jana, K. Eben and M. Maly et al., A statistical model for the estimation of natural gas consumption, Applied Energy 85 (2008), pp. 362-370.

[10] B. Marek, K. Ondřej, P. Emil and M. Marek, A nonlinear mixed effects model for the prediction of natural gas consumption by individual customers, International Journal of Forecasting 24 (2008), pp. 659-678. 
[11] B.B. Jiang, W.Y. Chen, Y.F. Yu, L. Zeng and V. David, The future of natural gas consumption in Beijing, Guangdong and Shanghai: an assessment utilizing MARKAL, Energy Policy 36 (2008), pp. 3286-3299.

[12] A.M. Kiliç, Turkey's natural gas necessity, consumption and future perspectives, Energy Policy 34 (2006), pp. 1928-1934.

[13] M. Forouzanfar, A. Doustmohammadi, M. Menhaj and S. Hasanzadeh, Modeling and estimation of the natural gas consumption for residential and commercial sectors in Iran, Applied Energy 87 (2010), pp. 268-274.

[14] P. Primož, T. Marko, G. Edvard, G. Igor and P. Alojz, Forecasting risks of natural gas consumption in Slovenia, Energy Policy 35 (2007), pp. 4271-4282.

[15] J.S. David and M. Ricardo, Sensitivity of electricity and natural gas consumption to climate in the U.S.A. - methodology and results for eight states, Energy 10 (1997), pp. 987-998.

[16] J.S. David, N.R. Jesse and M. Ricardo, Natural gas consumption and climate: a comprehensive set of predictive state-level models for the United States, Energy 2 (1998), pp. 91-103.

[17] W.Y. Fung, K.S. Lam and W.T. Hung, Impact of urban temperature on energy consumption of Hong Kong, Energy 14 (2006), pp. 2623-2637.

[18] K. Qian, China's natural gas resources, Petroleum Industry Press, Beijing (1999).

[19] Y.C. Wang, J.M. Li, Y. Zhu and Q.R. Ren, A new method to predict the dynamic demand of gas consumption, Petroleum Planning and Engineering 9 (1999), pp. 87-89.

[20] W.L. Jiao, J.B. Jin, L.M. Lian and J.H. Cui, Time series model of predicting short period city gas load, Natural Gas Industry 22 (2002), pp. 92-94.

[21] Y.F. Tan, Establishment and solution about forecast model of city gas seasonal load, Gas and Heat 3 (2003), pp. 131-133.

[22] X. Wan, B.W. Li, Y. Yan and J.D. Jiang, Study on combined forecasts of Chongqing's natural gas market demand during 11th Five-Year plan period, Natural Gas Technology 1 (2007), pp. 82-84.

[23] J.C. Yin and Z.B. Liu, Study on prediction model of gas demand self-adapting optimization combination, Natural Gas Industry 24 (2004), pp. 167-169.

[24] J. Gao and X.C. Dong, Natural gas forecast with self-organizing data mining, Statistics and Decision 7 (2008), pp. 50-52.

[25] National Bureau of Statistics of China, China year book 2009, China Statistical Press, Beijing (2009).

[26] Z.P. Tao, Introduction to system dynamics (Chinese version), WuNan Publishing Company, Wuhan (2000).

[27] IEA, Natural gas in China market: evolution and strategy, IEA, Paris (2009). 